\title{
Multicolor electroluminescent devices using doped ZnS nanocrystals
}

\author{
K. Manzoor, S. R. Vadera, and N. Kumar ${ }^{\mathrm{a})}$ \\ Defence Laboratory, Jodhpur 342 011, India \\ T. R. N. Kutty \\ Material Research Centre, Indian Institute of Science, Bangalore 560 012, India
}

\begin{abstract}
Alternate-current electroluminescent (ac EL) devices based on doped ZnS nanocrystals emitting blue, green, and orange-red colors are reported. $\mathrm{ZnS}$ nanocrystals doped with $\mathrm{Cu}^{+}-\mathrm{Al}^{3+}$ and $\mathrm{Cu}^{+}-\mathrm{Al}^{3+}-\mathrm{Mn}^{2+}$ combinations were synthesized by wet chemical method at room temperature. The $\mathrm{ZnS}: \mathrm{Cu}^{+}, \mathrm{Al}^{3+}$ nanocrystals show blue $(462 \mathrm{~nm})$ and green $(530 \mathrm{~nm})$ EL emissions depending upon the presence and absence of sulphur vacancies, respectively. The orange EL emission $(590 \mathrm{~nm})$ is realized from $\mathrm{ZnS}: \mathrm{Cu}^{+}, \mathrm{Al}^{3+}, \mathrm{Mn}^{2+}$ nanoparticles by way of nonradiative energy transfer from $\mathrm{Al}_{\mathrm{Zn}}-\mathrm{Cu}_{\mathrm{Zn}}$ pairs to $\mathrm{Mn}_{\mathrm{Zn}}$. The EL devices show low turn-on voltage of $\sim 10 \mathrm{~V}$ ac @100 Hz. The mechanism of ac EL in $\mathrm{ZnS}$ nanocrystals has been explained wherein the excitation is attributed to the electric-field-assisted injection of electron-hole pairs from the surface regions into the interiors and their subsequent recombination therein causes emission.
\end{abstract}

Optical, electronic, and structural properties of semiconducting nanocrystals have acquired considerable importance because of their great potential for many versatile applications ranging from DNA markers to light emitting displays. ${ }^{1-4}$ The success in converting these properties into technologically viable products lies in the ability to synthesize highly pure, well characterized nanocrystals (NC) and fabricate device structures based on them. Recently, it has been shown that hybrid organic-inorganic light emitting devices consisting of semiconducting nanocrystals and polymeric materials can be constructed. ${ }^{5}$ Furthermore, quantum dot light emitting diodes based on single layer of $\mathrm{CdSe}^{6}$ or $\mathrm{ZnS}: \mathrm{Mn}^{7}$ nanocrystals incorporated into hole injecting polymers have also been reported. All these studies are mainly based on the concept of realization of $p-n$ junction in multilayered structures, consisting of II-VI nanocrystals and organic polymers, operational under direct current (dc). In this letter, we report, the realization of alternate-current electroluminescence (ac EL) from doped $\mathrm{ZnS}$ nanocrystals showing blue, green, and orange-red emission colors.

$\mathrm{ZnS}$ nanocrystals doped with $\mathrm{Cu}^{+}-\mathrm{Al}^{3+}$ and $\mathrm{Cu}^{+}-\mathrm{Al}^{3+}-\mathrm{Mn}^{2+}$ combinations have been prepared by an optimized aqueous colloidal precipitation method at room temperature. ${ }^{8}$ Although the available literature ${ }^{9}$ on doping of $\mathrm{Al}^{3+}$ in $\mathrm{ZnS}$ phosphors reported only the high temperature $\left(\sim 900^{\circ} \mathrm{C}\right)$ doping processes, the present work reports incorporation of $\mathrm{Al}^{3+}$ as a coactivator in $\mathrm{Cu}^{+}$activated $\mathrm{ZnS}$ nanocrystals through wet chemical reaction at room temperature in which the activator-coactivator charge compensation conditions are effectively utilized to achieve the doping. During the coprecipitation reaction, substitutional occupation of one $\mathrm{Cu}^{+}$ion at $\mathrm{Zn}^{2+}$ site causes deficiency of a positive charge for the charge neutralization. This can be compensated by the intake of an $\mathrm{Al}^{3+}$ ion (at $\mathrm{Zn}^{2+}$ site) having one excess positive charge. Therefore, when codoped, $\mathrm{Cu}^{+}$, and

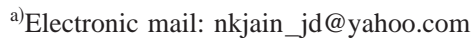

$\mathrm{Al}^{3+}$ ions can occupy the nearest-neighbor sites separated by one $\mathrm{S}^{2-}$ ion so as to form an electrically neutral impurity complex $\left(\mathrm{Cu}_{\mathrm{Zn}}-\mathrm{S}-\mathrm{Al}_{\mathrm{Zn}}\right)$. Strictly controlled reaction conditions, in which the copper is stabilized in $\mathrm{Cu}^{+}$state rather than $\mathrm{Cu}^{2+}$, and the high surface reactivity of nanoparticles help to realize the doping. Furthermore, to avoid any effect of halide ions, acting as another coactivator, we have used all halogen-free chemicals for the synthesis. The stoichiometric ratio, $X=\left[\mathrm{S}^{2-} / \mathrm{Zn}^{2+}\right]$, and doping concentrations were varied for each sample to realize the desired EL characteristics. Crystallinity of the samples, studied by using $\mathrm{x}$-ray diffractometer-Philips XRG-3000 fitted with $\mathrm{Cu} K \alpha \quad(\lambda$ $=1.54056 \mathrm{~nm}$ ) source, shown in Fig. 1(a) indicate the zincblende $(\beta-\mathrm{ZnS})$ crystal structure. Transmission electron microscopic (TEM, JEOL-JEM-200CX) image, Fig. 1(b), shows well isolated particles of average size $\sim 2 \mathrm{~nm}$. The concentrations of dopants present in the host lattice have

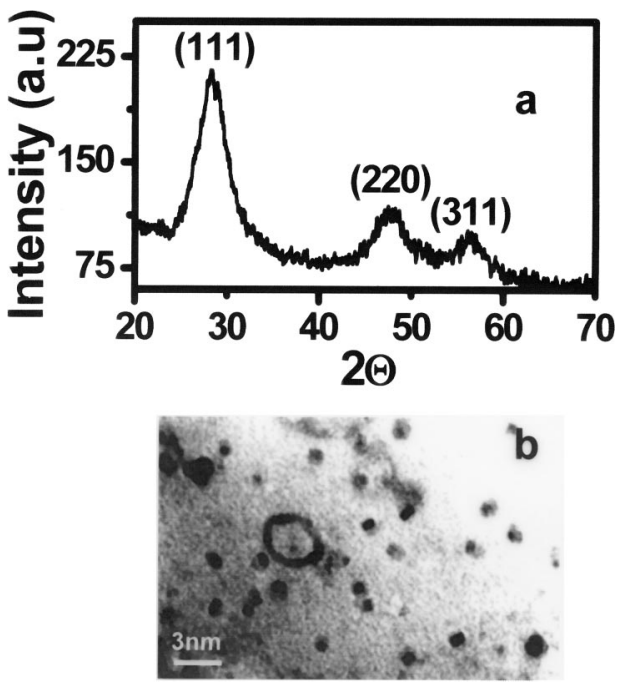

FIG. 1. (a) XRD pattern of ZnS nanoparticles, (b) TEM micrograph showing isolated nanoparticles of $\sim 2 \mathrm{~nm}$ size. 


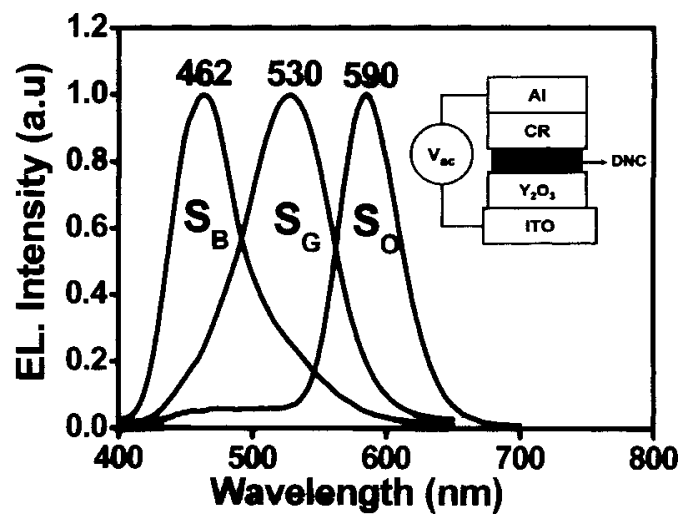

FIG. 2. EL spectra of doped $\mathrm{ZnS}$ nanocrystals $\left(S_{B}-\mathrm{ZnS}\right.$ : $0.13 \% \mathrm{Cu}^{+}, 0.1 \% \mathrm{Al}^{3+} ;[X<1], S_{G}-\mathrm{ZnS}: 0.13 \% \mathrm{Cu}^{+}, 0.1 \% \mathrm{Al}^{3+} ;[X>1]$, $\left.S_{O^{-}} \mathrm{ZnS}: 0.13 \% \mathrm{Cu}^{+}, 0.1 \% \mathrm{Al}^{3+}, 0.2 \% \mathrm{Mn}^{2+} ;[X>1]\right)$. Inset: schematic diagram of nanocrystals based ac EL device.

been estimated by atomic absorption spectrophotometer (AAS, Perkin-Elmer-2380).

The basic structure of our ac EL devices based on doped nanocrystals (DNC) is shown in Fig. 2 (inset). $300 \mathrm{~nm}$ thick $\mathrm{Y}_{2} \mathrm{O}_{3}$ layer was $e$-beam evaporated over an ultrasonically cleaned ITO coated glass substrate under vacuum $\left(10^{-6}\right.$ Torr) at $300^{\circ} \mathrm{C}$. Nanocrystals from a colloidal suspension were spray coated over the ITO/ $\mathrm{Y}_{2} \mathrm{O}_{3}$ substrate, kept at $50^{\circ} \mathrm{C}$ on a warm plate. The nanocrystal layer was dried at $60^{\circ} \mathrm{C}$ under vacuum. Uniform layer of highly packed nanocrystals (emissive layer) obtained in this way has been overcoated with a high dielectric $\left(\varepsilon_{r} \sim 22\right)$ cyano resin $(\mathrm{CR})$ by spray coating. Total thickness of DNC plus CR layer was maintained around $20-25 \mu \mathrm{m}$. Aluminum back electrode of $\sim 300 \mathrm{~nm}$ thick, $5 \mathrm{~cm}^{2}$ area was formed over the resin layer by $e$-beam evaporation while maintaining the substrate temperature $\sim 35^{\circ} \mathrm{C}$. Under ac activation, EL emission has been observed from the nanocrystal layer at a low voltage of $\sim 10$ V ac@100 Hz.

The electroluminescence (EL) and photoluminescence (PL) spectral recordings were carried out using a Spectrofluorometer, JASCO-FP-6500, at room temperature. Figure 2 shows EL spectra of doped nanocrystals. Strong blue EL emission with maximum at $462 \mathrm{~nm}(2.62 \mathrm{eV})$ has been obtained from $\mathrm{ZnS}: 0.13 \% \mathrm{Cu}^{+}, 0.1 \% \mathrm{Al}^{3+}$ prepared under $\mathrm{S}^{2-}$ deficient condition of $X=\left[\mathrm{S}^{2-} / \mathrm{Zn}^{2+}\right]<1 \quad\left(\right.$ sample- $\left.S_{B}\right)$. When the sample is prepared under $\mathrm{S}^{2-}$ excess conditions of $X>1$ (sample- $S_{G}$ ) the EL emission changes to green with maximum at $\sim 530 \mathrm{~nm}(2.30 \mathrm{eV})$. Incorporation of $\mathrm{Mn}^{2+}$ into the lattice together with $\mathrm{Cu}^{+}$and $\mathrm{Al}^{3+}$ under $\mathrm{S}^{2-}$ excess precipitation (sample- $S_{O}: \mathrm{ZnS}: 0.13 \% \mathrm{Cu}^{+}, \quad 0.1 \% \mathrm{Al}^{3+}$, $\left.0.2 \% \mathrm{Mn}^{2+}\right)$ resulted orange-red EL at $590 \mathrm{~nm}(2.12 \mathrm{eV})$. However, no ac EL was observed from $\mathrm{ZnS}: \mathrm{Mn}^{2+}$ nanocrystals. Furthermore, for all values of $X<1$, blue emission bands were always present in the EL spectrum irrespective of the type or concentration of dopants. The PL studies carried out with variations in $\mathrm{Cu}^{+} / \mathrm{Al}^{3+}$ ratio (concentration of $\mathrm{Al}^{3+}$ is varied from $0-0.1$ at. \%) and stochiometric conditions are shown in Fig. 3. At sulphur deficient preparatory conditions of $X<1$, in the absence of $\mathrm{Al}^{3+}$ coactivator, only blue (465 $\mathrm{nm})$ emission is present in the sample. However, incorporation of $\mathrm{Al}^{3+}$ resulted in the appearance of a green side band at $525 \mathrm{~nm}$ whose intensity increases with the concentration
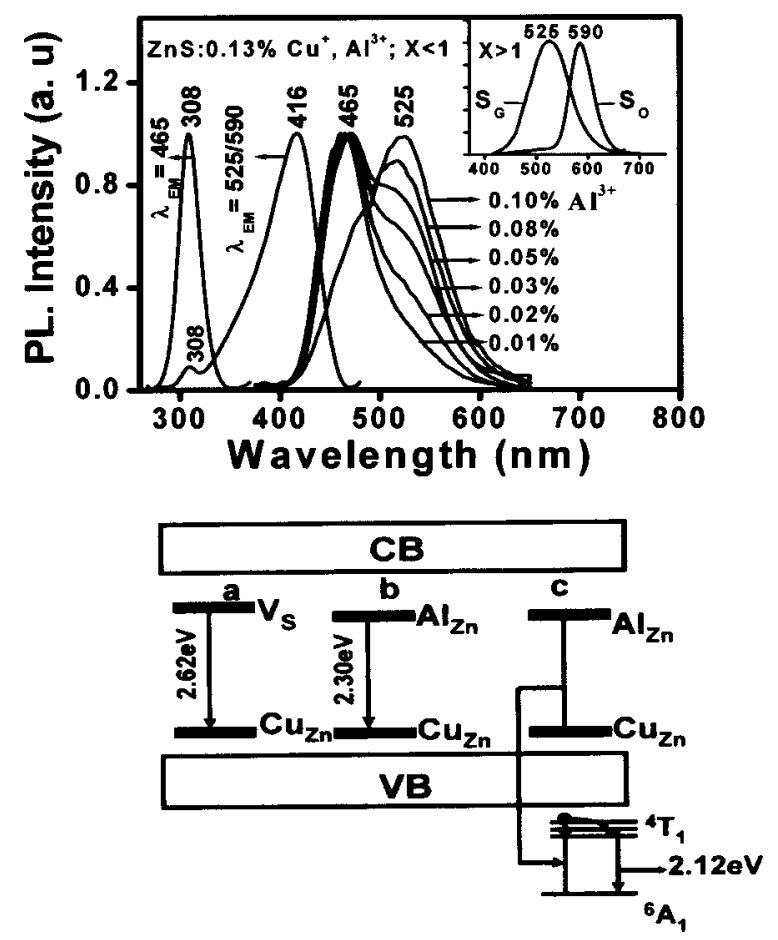

FIG. 3. PL spectra of doped $\mathrm{ZnS}$ nanocrystals with change in $\mathrm{Cu}^{+} / \mathrm{Al}^{3+}$ ratio and stoichiometric condition $X=\left[S^{2-} / \mathrm{Zn}^{2+}\right]$. Schematic: energy level diagram showing three possible electronic transitions corresponding to multicolor emissions from doped $\mathrm{ZnS}$ nanocrystals: (a) Blue emission at 2.62 $\mathrm{eV}$ due to $V_{S} \rightarrow \mathrm{Cu}_{\mathrm{Zn}}$ transition; (b) green emission at $2.30 \mathrm{eV}$ from $\mathrm{Al}_{\mathrm{Zn}}$ $\rightarrow \mathrm{Cu}_{\mathrm{Zn}}$; and (c) orange emission at $2.12 \mathrm{eV}$ due to nonradiative energy transfer from $\mathrm{Al}_{\mathrm{Zn}} \rightarrow \mathrm{Cu}_{\mathrm{Zn}}$ pairs to $\mathrm{Mn}_{\mathrm{Zn}}$ centers.

of $\mathrm{Al}^{3+}$. At $0.1 \% \mathrm{Al}^{3+}$, the green band becomes dominant making the blue band as side band. The increase in sulphide ion concentration $(X>1)$ caused remarkable reduction in the efficiency of the blue side band and the green emission becomes spectrally more symmetric as shown in Fig. 3 (inset). The incorporation of $\mathrm{Mn}^{2+}$ into the lattice at this stage resulted in the orange emission at the cost of green emission. The excitation spectra (PLE) for blue and green/orange emission show different excitation process in which the blue emission is contributed by the band-to-band transition of the host $(308 \mathrm{~nm} / 4 \mathrm{eV})^{8}$ whereas the green and orange emission is excited by intra-band-gap transition at $416 \mathrm{~nm} / 2.97 \mathrm{eV}$, which has been observed only in $\mathrm{Cu}^{+}-\mathrm{Al}^{3+}$ containing $\mathrm{ZnS}$.

Efficient blue emission at $\mathrm{S}^{2-}$ deficient condition and green emission at $\mathrm{S}^{2-}$ excess condition clearly indicates the role of sulphur vacancies $\left(V_{S}\right)$ in determining the emission properties of $\mathrm{ZnS}$ nanophosphors. $V_{S}$ can trap the electrons and form shallow donor levels below the conduction band (CB) edge whereas $\mathrm{Cu}^{+}$, substitutionally situated at $\mathrm{Zn}^{2+}$ site $\left(\mathrm{Cu}_{\mathrm{Zn}}\right)$, traps the holes and form an acceptor level above the valance band $(\mathrm{VB})$ edge. ${ }^{10} \mathrm{Al}^{3+}$ ions substituted for $\mathrm{Zn}^{2+}\left(\mathrm{Al}_{\mathrm{Zn}}\right)$ will also create donor levels but deeper in position than that of Vs. ${ }^{11}$ Band-gap energy diagram shown in Fig. 3 schematically illustrate different electronic transitions corresponding to multiple emissions from $\mathrm{ZnS}$ nanophosphors. Our results indicate the presence of a competitive donor-acceptor (D-A) type emission process between $V_{S}$ $\rightarrow \mathrm{Cu}_{\mathrm{Zn}}$ and $\mathrm{Al}_{\mathrm{Zn}} \rightarrow \mathrm{Cu}_{\mathrm{Zn}}$. In nanocrystals having larger concentrations of $V_{S}$ centers, the $V_{S} \rightarrow \mathrm{Cu}_{\mathrm{Zn}}$ process is more efficient resulting in emission at $462 \mathrm{~nm}$. However, as the va- 


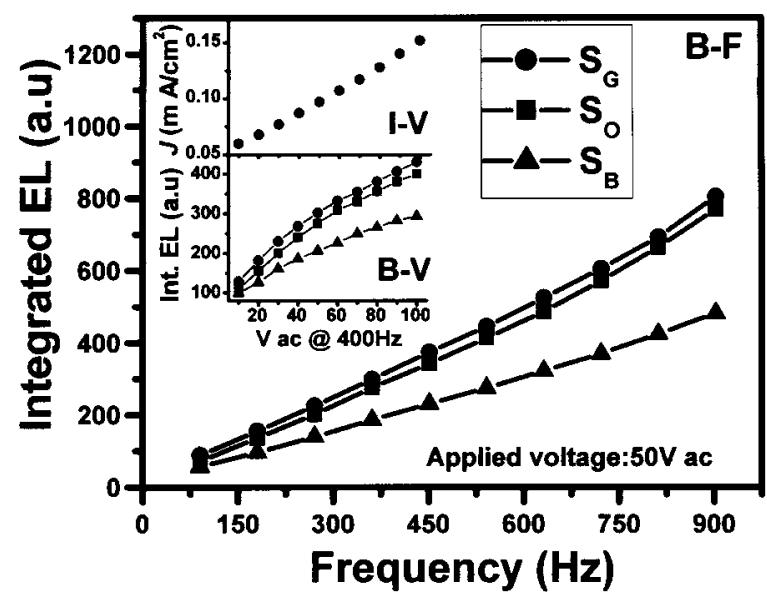

FIG. 4. Brightness-frequency $(B-F)$, brightness-voltage $(B-V)$, and current-voltage $(I-V)$ characteristics of nanocrystals based ac EL devices.

cancy states are annihilated by preparing samples at $\mathrm{S}^{2-}$ excess condition, together with an optimum $\mathrm{Cu}^{+}-\mathrm{Al}^{3+}$ doping, the $\mathrm{Al}_{\mathrm{Zn}} \rightarrow \mathrm{Cu}_{\mathrm{Zn}}$ transition becomes dominant resulting in emission at $530 \mathrm{~nm}$. The corresponding excitation at an intra-band-gap position can be ascribed to $\mathrm{Cu}_{\mathrm{Zn}} \rightarrow \mathrm{Al}_{\mathrm{Zn}}$ electronic transition. The appearance of the same excitation band for $\mathrm{Mn}^{2+}$ related ${ }^{11}$ orange emission clearly indicates an effective nonradiative energy transfer from $\mathrm{Cu}_{\mathrm{Zn}}-\mathrm{Al}_{\mathrm{Zn}}$ pairs to $\mathrm{Mn}_{\mathrm{Zn}}$. The fact that orange ac EL was not observed in the absence of $\mathrm{Cu}^{+}-\mathrm{Al}^{3+}$ dopant pair also indicates the process of energy transfer prevailing in the system.

The brightness-voltage- $(B-V)$, brightness-frequency $(B-F)$, and current-voltage $(I-V)$ characteristics of the EL devices are shown in Fig. 4. The EL intensity increases with the applied voltage as well as frequency. Green and orange emitting devices show better efficiencies than the blue. The increase in EL intensity does not show any sign of saturation with the frequency, whereas the intensity tends to level-off above $100 \mathrm{~V}$. $I-V$ characteristics show a nominal increase in current density with the applied voltage. These results suggest that the nanophosphors based ac EL devices are better suited for low voltage applications.

Following the micrographic observations of Gillson and Darnel, ${ }^{12}$ EL mechanism in bulk ZnS phosphors has been explained by Fischer $^{13}$ using the bipolar double injection model. The $\mathrm{Cu}$-decorated lattice dislocations, generated dur- ing the high temperature $\left(>900{ }^{\circ} \mathrm{C}\right)$ firing process is the key factor leading to ac EL in bulk $\mathrm{ZnS}$ phosphors. However, in case of nanocrystals, the same mechanism does not hold good because there cannot be large concentrations of dislocations in the absence of any high temperature process as well as very small size of the crystallites. Therefore, we believe that, in nanocrystals having high surface to volume ratio, the concentration of $\mathrm{Cu}^{+}$ions substitutionally situated at $\mathrm{Zn}^{2+}$ site can be larger at the surface regions than the interior. This will result in charge accumulated regions at the nanoparticle surface. When an ac voltage is applied, field intensification takes place at the copper rich surface and causes electron-hole pair injection into the interiors. The electrons will be trapped either at the sulphur vacancy centers $\left(V_{S}\right)$ if their concentration is larger or at $\mathrm{Al}_{\mathrm{Zn}}$ centers whereas the holes will be trapped at $\mathrm{Cu}_{\mathrm{Zn}}$ acceptor centers. During the field reversal, the electrons released from the donor sites combine radiatively with the holes resulting in ac EL emission from $\mathrm{ZnS}$ nanophosphors.

In summary, we have demonstrated low voltage ac electroluminescence from $\mathrm{Cu}^{+}-\mathrm{Al}^{3+}$ and $\mathrm{Cu}^{+}-\mathrm{Al}^{3+}-\mathrm{Mn}^{2+}$ doped $\mathrm{ZnS}$ nanophosphors. By controlling the defect chemistry and doping concentrations, the EL emission color has been varied from blue to orange-red. Charge accumulation at the copper-rich nanoparticle surfaces leading to tunneling of charges from the surface to interiors at high electric field is proposed for ac EL mechanism in nanophosphors.

${ }^{1}$ A. P. Alivisatos, Science 271, 933 (1996).

${ }^{2}$ R. N. Bhargava and D. Gallagher, Phys. Rev. Lett. 72, 416 (1994).

${ }^{3}$ W. C. W. Chan and S. Nie, Science 281, 2016 (1998).

${ }^{4}$ M. V. Artemyev, V. Sperling, and U. Woggon, J. Appl. Phys. 81, 6975 (1997).

${ }^{5}$ V. L. Colvin, M. C. Schlamp, and A. P. Alivisatos, Nature (London) 370, 354 (1994).

${ }^{6}$ S. Coe, W. K. Woo, M. G. Bawendi, and V. Bulovic, Nature (London) 420, 800 (2003).

${ }^{7}$ H. Yang, P. H. Holloway, and B. B. Ratna, J. Appl. Phys. 93, 586 (2003).

${ }^{8}$ K. Manzoor, S. R. Vadera, N. Kumar, and T. R. N. Kutty, Mater. Chem. Phys. 82, 718 (2003).

${ }^{9}$ S. Shionoya and W. M. Yen, Phosphor Handbook (CRC, Washington, DC, 1999).

${ }^{10}$ A. S. Marfunin, Spectroscopy, Luminescence and Radiation Centers in Minerals (Springer, New York, 1979).

${ }^{11}$ R. N. Bhargava, J. Lumin. 70, 85 (1996).

${ }^{12}$ J. L. Gillson and F. J. Darnell, Phys. Rev. 125, 149 (1962).

${ }^{13}$ A. G. Fischer, J. Electrochem. Soc. 113, 449 (1966). 